\title{
Management of Environmental Protection and Sustainability in the Islamic Revolution
}

\author{
Yaddollah Sepehri*, Gholam Reza Montazeri \\ Islamic Sciences, Gorgan University of Agricultural Sciences and Natural Resources, Gorgan, Golestan Province, Iran \\ Email: ${ }^{\star}$ yaddollah_sepehri@yahoo.com
}

How to cite this paper: Sepehri, Y. and Montazeri, G.R. (2019) Management of Environmental Protection and Sustainability in the Islamic Revolution. Open Journal of Ecology, 9, 43-49. https://doi.org/10.4236/oje.2019.93005

Received: February 18, 2019

Accepted: March 17, 2019

Published: March 20, 2019

Copyright $\odot 2019$ by author(s) and Scientific Research Publishing Inc. This work is licensed under the Creative Commons Attribution International License (CC BY 4.0).

http://creativecommons.org/licenses/by/4.0/

(c) (i) Open Access

\begin{abstract}
Conservation of environmental resources and divine merits does not mean the absence of exploitation or the minimal use of it, but to use it optimally and seamlessly. Therefore, awareness and education in the field of environmental ethics can have a spiritual guarantee in the light of faith and piety; considering the religious teachings and the experiences of the executives and officials of the Islamic Revolution that become more colorful topics such as environmental justice, environmental ethics, environmental degradation, health and optimal consumption. The expansion of morality is considered to be in the context of human-environmental relations as a revolutionary opportunity and an environmental imperative. In fact, the interests of man are in balance with the interests of other beings; as a result, there are solutions to protect the inhumane community against human harm. In this project, we used of library methods, review and integration on the basis of articles and environmental studies. The results of this study indicate that there is a relationship between religious beliefs and revolutionary approaches to the environment and environmental ethics. The mentioned verses and narratives, the leadership's recommendations all emphasize on environmental protection; and authorities have done this knowledge and information in the best way to raise the level of education. The results of the research show the upward trend in the environment after the Islamic Revolution in the process of approving and drafting laws.
\end{abstract}

\section{Keywords}

Environment, Revolutionary Approach, Religious Beliefs and Environmental Ethics

\section{Introduction}

In the current era, the most important human concern is the problems of nature 
and the human environment. A man is provided the destruction to his own hands on earth and it is put to death and destroys his life, he has taken the tranquility of the body and soul. In addition, it has destroyed the lives of other beings.

In fact, all international organizations are trying to somehow reduce the destructive effects of this crisis, but in this matter, they have succeeded in asking a question that is not satisfactory. By studying the views of the scholars of these schools, it turns out that some suggest that they apply law and use legal methods. Others see the government's economic reform as effective; to mitigate the effects of the crisis, but the vast majority of experts consider referring to morality as the best and most effective way to prevent and believe that the environmental crisis in today's world is, in fact, a moral crisis and should lead to a moral solution to it. The attempt to achieve ethics as a regulator of human intervention in the environment is not new and has been a matter of great concern, particularly in the 1960s, which has emerged as an acute crisis of the environment.

Environmental ethics is a branch of applied philosophy that focuses on environmental issues with a religious approach; our view in this article is environmental management based on Islamic concepts, and its sustainability after the Islamic revolution of Iran.

The nature and position of the environment are evident in Islamic philosophy and verses and traditions. The view of Islam about the relationship between man and the environment is that this relationship is not a form of violence, but an interconnected relationship. God conquers the human relationship with nature; if a person betrays in lending; the collection of the cosmic system does not obey him [1].

Islamic thought is the continuation of the perfection of all beings. On the other hand, in Islam, nature is as a verse and a divine manifestation. Indeed, in the Islamic religion, the elements of the universe of existence express the existence of a unique creator [2].

In this research, we have tried to focus on the desired effects in the field of environmental protection, according to religious beliefs, the religion of Islam and the phenomenon of the Islamic Revolution. The Islamic Revolution of Iran and the strategic documents approved in the post-revolution era. The organization has played an integral role in preserving and enhancing environmental ethics and on the basis of the repeated recommendations of the system officials and the proposed programs and implementation.

\section{Materials and Methods}

In this research, library and documentary methods were used. Based on this, we reviewed the books and articles published and documents in this field. After identifying the sources and documents and evaluating them, they were matched to the extent of the relationship with the desired axis and then the classification and categorization of resources based on their content and finally the conclusion of the classified information. 
The project used library methods, review and compilation based on articles and compilation of content in order to present the effects of religious beliefs on the thoughts and ideas of religious elders in the field of the environment.

\subsection{Human and the Environment in the Opinion of Islam}

In recent environmental crises, many researchers have begun an attempt to examine the causes of human hostile behavior with its own nature.

Considering the theory of monotheism as the origin of the Islamic worldview, this theory states that the universe was the creation of the divine will and it was created with the divine purpose.

Human beings are free to use resources and use it as the caliph of God and Ashraf Creatures. In fact, he is the trustee of these earthly facilities created by God for the comfort and comfort of his other creatures and is definitely expected to do well in his responsibility to preserve them.

The environment is a trust for the human being and he should not use his powers and abilities against the environment. In fact, instead of protecting and protecting the environment, humans tend to dominate and overcome the natural state [3].

The emergence of environmental ethics is the emerging phenomenon and the earliest Muslim thinker who argued in this area that Iranian professor Seyed Hassan Nasr, writing in collaboration with Fritahov, Shvan, Titus Burkhart and René Guénon, wrote this opinion.

Based on the Qur'anic teachings to preserve the environment and its optimal exploitation, it should express religious beliefs and beliefs, religious recommendations and assurances, efforts to realize them in the human society, the nation and the state as a mechanism of monitoring and favorable support, and Effective [4].

Unfortunately, pollution is now a feature of the urban environment in many countries. Smoke from car fuel is the biggest contributing factor. But domestic and industrial use of hydrocarbons is also another important factor. Other factors include increasing noise in urban environments and its destructive effects on city residents [5].

\subsection{The Role of Islamic Teachings in Reducing Environmental Crises}

Environmental degradation is one of the three major human concerns around the world. As a result of accidents, there are widespread effects that lead to physical damage, life damage, or massive changes in the environment. These events can cause a lot of damage to property, life, economics and people's culture.

From the perspective of Islam, he is the absolute owner of nature and creatures, God the Almighty and his successor on earth.

A person's representation requires that he be seized on the ground, as if he 
were a depositor. Nature is the heritage of all human beings and inherited from generation to generation [6] (Shokohi, 1994).

From the perspective of the Holy Qur'an, all beings of nature are also sacred because all the components of nature say the mention of God. Accordingly, humans are responsible for everything, including animals and the surrounding environment. The most important task of man towards nature is to correct the land and avoid its destruction.

Civil and settlement is one of the means of land reform. The purpose of civilization on earth is to ensure the principles of the environment for the life of all living things. The rules of Islam are abundant and diverse about the environment. According to these rules, humans are obligated to refrain from contaminating water and soil and air, to plant trees and behave kindly and with animals, and to protect them from biodiversity [7] (Tabarsi, $1412 \mathrm{AH}$ ).

\subsection{Environmental Reforms after the Islamic Revolution}

The environmental crisis has changed the situation with the advent of industrial revolution and scientific, technical and medical progress. The construction and application of a variety of industries, vehicles and smoke generators, and the creation of sewage and hazardous wastewater, is the result of human machine life in recent decades.

According to United Nations statistics, about $98 \%$ of carbon dioxide and other harmful atmospheres are attributable to industrial countries and only $2 \%$ of that share of third world countries [8] (Matin, 1997).

Regarding environmental degradation as a major global issue, especially in the Islamic world, the importance of addressing clearly identifies issues related to environmental issues related to religious beliefs, the emergence of the phenomenon of the Islamic Revolution.

The Islamic Revolution of Iran involves unique features that have made it different from other major revolutions in the world. The most important features are: religious (Islamic) being, leadership influence, corporal learning, independence and lack of reliance on any foreign power, regional and global reflection of the Islamic Revolution.

By comparing the results and functions of the Islamic Revolution in the scene of the operation with respect to the pre-revolutionary period and the analogous countries, on the one hand, it shows the great and undeniable changes that have arisen from the revolution in previous years, and on the other hand, it depicts an idealistic and ideal perspective. For the future, by reviewing the laws of the development plans (six programs) before the Islamic Revolution and the development plans (six programs) after the Islamic Revolution, what is evident is the upward trend and the development of environmental rights in the process of drafting and approval of program laws [8] (Matin, 1997).

As we study the rules in the post-revolutionary context, regardless of the content analysis, we observe that the ecological status of the cultivar certificate is 
one note (Note 13) in the first development plan law of a total of 52 notes in the fourth development plan of one Of the six axes called environmental protection, land use planning and regional equilibrium, a total of 15 articles out of 161 articles of the Fourth Environmental Law have been devoted to environmental issues, along with 14 other issues, the need to respect environmental issues Legislator [9] (Law Office, 2009).

The process has been moving forward in a relatively successful direction in terms of environmental considerations with developmental plans to achieve sustainable development that the definitive success of these programs will depend on its full implementation. It should be acknowledged that the fulfillment of all environmental objectives contained in development plans, especially in the fourth development plan with an environmental perspective, will include strengthening the basic infrastructure, coordination between environmental affairs, national determination and providing an appropriate framework for public participation. The specialty of NGOs that we have seen is in the fifth and sixth development plans.

\subsection{Environment in Internal Laws before and after the Islamic Revolution}

Before the Islamic Revolution, the only one has been devoted to generalities on protecting forests in the country's developmental programs from environmental issues and yet after the revolution, the Supreme Leader of the Islamic Revolution Ayatollah Khamenehi, in the implementation of paragraph 1 of article 110 of the Constitution, they sent letters to the executive directors of the country (general environmental policies).

Given the importance of human life and its direct relation with environmental issues, environmental problems have become the greatest challenge facing the present-day life, Hence, the issue of the environment is the concern of international organizations, governments and NGOs and NGOs, and most importantly citizens. As far as investigated, the subject of the research has never been thoroughly investigated before, but has been investigated in a limited way.

Understanding planners and decision makers, economic and industrial activists, managers of different sectors of NGOs and environmentalists from the legal status of environmental issues, especially given that some environmental issues can have a criminal dimension, can play a significant role in the development of environmental protection culture Life as well as improving the relationship between development issues and the environment.

Regarding the survey, it was well-known that the Iranian legislator has paid attention to environmental issues since 1956. Since then, the Environmental Protection and Environmental Protection Act of 1975 has been approved.

With the victory of the Islamic Revolution, environmental issues were brought to the attention of the Revolutionary Council, as approved by them, they approved the bill on the punishment of unauthorized fishing in 1979, and approved the bill on the conservation and extension of green spaces in the cities in 
1979 with verdicts Attention.

The constitution has, in its fifty principle, considered an ideal in the field of the environment that demonstrates the special attention of the drafters of the constitution to environmental issues [10] (Law Office, 2011).

In the five-year plans of the country, the status of the environment has increased considerably. In post-revolution development programs, in both pre-revolutionary development plans, both quantitatively and qualitatively and it is clear that the impact of the introduction of environmental programs at the macro level has had a significant impact on environmental performance at the community level.

\section{Result}

In the country of the Islamic Republic of Iran, developed and developed economic, social and cultural programs in the form of 5-year programs, began in 1948 and so far. Considering the emergence of the phenomenon of the Islamic Revolution and the adherence to the religion of Islam in society, according to the recommendations of the Supreme Leader of the Islamic Revolution and the Supreme Leader, verses and religious traditions, the special significance of the development and development of the earth and this attitude helped improve the environment and changed the face of man from the destroyer to the citizen and protecting the environmental security of the change. The Islamic Revolution of Iran has always been used as a pilot in the region and in the world.

The importance of the issue of the environment and the view of the great leadership of the revolution shows the influence of revolution and religious beliefs in strengthening and institutionalizing the proper culture of the environment and the application of religious knowledge and environmental ethics with Islamic-Iranian modeling.

In today's world, despite facing economic and social crises, such as population growth, poverty, unemployment, social harm, inequity, they have become a big dilemma (disregard for culture and morality) environmental and lack of knowledge and insight to preserve the environment at all levels and levels of society.

In the field of environmental ethics and the use of religious beliefs and teachings after the Islamic Revolution, there have been many activities. Empowerment in the areas of ethics and its development can be very effective in promoting the cultural level and impacting on other segments of society.

Ultimately, the destruction of the environment caused by human intervention in nature has become a global crisis that all countries in the world are not safe from its consequences, and in order to contain this important issue, all countries must deal with and prevent deterioration.

\section{Conflicts of Interest}

The authors declare no conflicts of interest regarding the publication of this paper. 


\section{References}

[1] Javadi Amoli, A.S. (2007) The Environmental Culture Is Blended with God's Successor. The International Conference on the Environment, Religion and Culture, Iran.

[2] Naghizadeh, M. (2009) Principles of Religious Art in Islamic Culture. Vol. 1, Islamic Culture Publishing Office.

[3] Georjy, A. (1983) Islam and the Environment. Journal of Nursing, No. 4.

[4] Ayatollahi, M.T. (1992) General Health Issues in Islam, Islamic Republic of Iran, Astan Quds Razavi Islamic Studies Foundation. Mashhad.

[5] Biomont, et al. (1991) Middle East. Translation by Mohsen Shan Hachi, et al. Astan Quds Razavi Publishing House, Mashhad.

[6] Shokohi, H. (1994) Geography and Religion. Quarterly Geography Quarterly, No. 30.

[7] Tabarsi, P. (1412BC) Bayan Complex in the Interpretation of the Qur'an, Beirut. The Foundation of Arab History, Vol. 4.

[8] Matin, A. (1997) Global Biosphere Threat, Research and Development Journal, Quarterly, Research and Training on Jihad-e-Building, No. 13.

[9] Law Office (2009) Commission on Agriculture, Water and Natural Resources, Eighth, Second Year.

[10] Law Office (2011) Eighth Year, Fourth Year, Registration Number 579. 